\title{
THE SUBJECTIVE ASSESSMENT OF TRAINING LOAD IN THE TRAINING PROCESS OF YOUNG SKIERS
}

\author{
Els-Brett Heinsoo, Jarek Mäestu \\ Institute of Sport Biology and Physiotherapy, University of Tartu, Estonia
}

\begin{abstract}
The aim was to investigate how the 10-point intensity scale can be used in characterizing training intensities in young skiers and whether perceptions of training intensity of coach and athlete are related. 13 young crosscountry skiers, aged 14-17 participated. During the 17-day training camp their training data and the subjective intensity perceptions of the coaches and athletes were recorded. Based on the time-in-zone method the subjects trained $71.8 \%$ in zone $1,27.1 \%$ in zone 2 and $2.1 \%$ in zone3. According to subjective assessment, $74.1 \%$ of trainings were done in zone1, 19.0 in zone 2 and $8.0 \%$ in zone 3 . There were no significant differences between intensity distributions between zone1, but according to subjective scale, subjects trained significantly less in zone 2 and significantly more in zone3. Subjective assessments of coach and athletes indicated the highest correlations $(\mathrm{p}<0.05)$ between zone $2(\mathrm{r}=0.80)$ and interval trainings $(\mathrm{r}=0.71)$ and were lower for basic $(r=0.25)$ and recovery trainings $(r=0.35)$. In conclusion, 10-pt scale to describe training intensities is a practical method for young athlete training zone distribution assessment.
\end{abstract}

Keywords: young skiers, training intensity, subjective assessment, training load

\section{INTRODUCTION}

Endurance training involves the manipulation with training volume, intensity and frequency. The great emphasis during the preparation of endurance athlete is on training volume with low training intensity. Endurance athletes further divide their trainings into different training zones to tar- 
get their trainings for different energy systems. It has been shown that the distributions of the training zones between different endurance disciplines present the $80: 20$ model with approximately $80 \%$ of trainings at the intensities around or below the anaerobic threshold [12]. However, young athletes train on slightly higher intensities in order to have sufficient training load [13]. The optimal distribution of those intensities is very important regarding excessive training stress, as training at too high intensities might lead to overtraining of the athlete [10]. Therefore, careful monitoring of training intensities is vital also in young athletes.

The most well-known method of monitoring of training intensity is heart rate. However, heart rate monitors are not always present or they are forgotten to put on if training of young athlete is considered. Therefore, an alternative, practical method is suggested. Previous research has indicated that the assessment of the subjective effort during training can be considered as an alternative method for evaluating the training intensity in adult $[8,13]$ and junior level endurance athletes [11]. Foster et al. [8] developed from the 10 point category scale [3] a modified scale to indicate the subjective evaluation of the used intensity. Using this scale, the question will be asked approximately $30 \mathrm{~min}$ after the end of the training session: "How hard was your workout?" Very high correlations between the actual training intensity and the subjective assessment were seen also in the replication studies $[4,9$, 11]. Seiler and Kjerland [13] further investigated the possibility to use the scale to indicate in which particular intensity zone the athlete was during the training. Their study with elite cross-country skiers indicated that the subjective assessments were very highly correlated with the method that was called "the session goal" method for evaluating the overall intensity of training. However, there is no data, how the subjective assessment of training intensity can be used in younger endurance athletes in order to characterize their training intensity and the distribution to intensity zones.

Young athletes usually train in groups, meaning that during the workout they train together also at longer distances. This, however, leads to the situation that the intensity of the training will not be similar to all the athletes and for those athletes who want to "keep-up" with the others, training load might became too high if trainings like this persist for longer period. The comparison between the coach's perceptions of the training intensity and the athlete evaluation might be also beneficial. Therefore, the aim of the current study was to investigate how the 10-point intensity scale developed by Foster et al. [8] can be used in characterizing the training intensities in young cross-country skiers and how the perceptions of coaches and athletes regarding the training intensities are related. 


\section{MATERIALS AND METHODS}

\section{Participants}

13 young cross-country skiers ( 10 males and 3 females) aged $14-17$ yrs took part in this investigation (Table 1). The subjects had been training cross-country for at least 2 years. The study procedures and methods were explained to the subjects and their parents and a written informed consent was taken from the parents and the children gave verbal assent. The study was conducted according to the declaration of Helsinki and approved by the Ethical Committee of University of Tartu

Table 1. Main characteristics of the subjects $(n=13)$.

\begin{tabular}{lcc}
\hline & Mean \pm SD & Distribution \\
\hline Age (years) & $15.5 \pm 1.3$ & $14-17$ \\
\hline Height $(\mathrm{cm})$ & $177.8 \pm 10.5$ & $163-201$ \\
\hline Weight $(\mathrm{kg})$ & $65.6 \pm 10.8$ & $48-84$ \\
\hline Experience (years) & $4.7 \pm 1.8$ & $2-7$ \\
\hline
\end{tabular}

\section{Procedures}

The data were collected during the 17-day first snow camp in northern Finland. During the study no changes were made in their initial training plan that was composed by their personal coach. The following parameters were recorded during the study:

1. The discipline (cross-country skiing, running, resistance training, etc.);

2. The type of training (basic endurance, interval or speed training, recovery training);

3. The volume of the trainings (time, distance);

4. The intensity of the trainings (heart rate, 10-pt scale).

Resistance trainings were not calculated during the analysis of training intensities. Heart rate recording (Polar or Suunto sporttester) was used to categorize training intensities either below aerobic threshold (zone1), between aerobic and anaerobic threshold (zone2) or higher than anaerobic threshold (zone3) [13]. The distributions to different zones were found using the time in zone method, where all heart rate values were saved into particular intensity zone. Individual intensity zones were calculated based on the regular medical testing of the athletes during the autumn, not more 
than 1 month preceding the study. For those subjects whose threshold values were not available, training zones were calculated according to the following formula: aerobic threshold $=0.7 \times(220$-age); anaerobic threshold $=0.85 \times$ (220-age) [2]. The corresponding heart rate values are presented in Table 2.

Table 2. Heart rate values corresponding to intensity zones.

\begin{tabular}{lcc}
\hline \multicolumn{1}{c}{$\mathrm{n}=13$} & Mean \pm SD & Distribution \\
\hline Aerobic threshold & $147.1 \pm 6.6$ & $142-167$ \\
\hline Anaerobic threshold & $176.5 \pm 4.7$ & $173-188$ \\
\hline
\end{tabular}

10-pt scale was used to assess subjectively the training intensity of each workout [8]. $30 \mathrm{~min}$ after the workout the subjects were asked: "How hard was your workout?" and the scale was shown with the anchors placed according to Seiler and Kjerland [13] (Table 3). The scale has been translated to Estonian and used in different studies before. The same scale was used by the coach to evaluate training intensity of the planned workout. Based on previous research the intensity scale was divided into three zones as follows: zone1 values $\leq 4$; zone 2 values between 4 and 7 ; and zone 3 values $>7$ [13].

Table 3. 10-pt scale for the measurement of training intensity.

\begin{tabular}{cl}
\hline Numeric value & \multicolumn{1}{c}{ Description } \\
\hline 0 & Rest \\
\hline 1 & Very light \\
\hline 2 & Light \\
\hline 3 & \\
\hline 4 & Moderate \\
\hline 5 & Hard \\
\hline 6 & \\
\hline 7 & Very hard \\
\hline 8 & Very, very hard \\
\hline 9 & Almost maximal \\
\hline 10 & Maximal \\
\hline
\end{tabular}




\section{Statistical analysis}

Data were analyzed using the SPSS 20.0 software (IBM). Means and standard deviations $( \pm S D)$ were calculated. Differences between the parameters were evaluated using the Pearson correlation analysis and Independent Sample t-test. The statistical significance was set at $\mathrm{p}<0.05$.

\section{RESULTS}

During the 17 days 364 trainings were recorded. Each athlete performed $28.0 \pm 2.6$ workouts. The average training volume for the athletes was $48.0 \pm 6.4$ hours and they covered $511.5 \pm 119.2$ kilometers. The average training volumes for each training discipline are presented in Table 4.

Pure resistance trainings during this training period were not made. Resistance exercises were made only at the end of $1.9 \pm 0.3$ workouts for $24.4 \pm 4.0$ minutes.

The average length of the cross-country sessions was $110.3 \pm 29.9 \mathrm{~min}$ and $34.7 \pm 5.2 \mathrm{~min}$ for running session. The average distances were $19.9 \pm 7.6 \mathrm{~km}$ and $4.8 \pm 1.2 \mathrm{~km}$ for cross-country skiing and running, respectively. From 364 trainings $44.2 \%$ were basic endurance workouts and $21.7 \%$ speed and interval workouts (Table 5).

Tabel 4. Mean training volumes $(\mathrm{X} \pm \mathrm{SD})$ of different sport disciplines.

\begin{tabular}{lccc}
\hline & Training times & Training hours & Distance $(\mathbf{k m})$ \\
\hline Cross-country skiing & $25.0 \pm 2.4$ & $45.8 \pm 6.2$ & $496.7 \pm 117.4$ \\
\hline Running & $3.0 \pm 0.4$ & $1.7 \pm 0.2$ & $14.4 \pm 2.8$ \\
\hline Nordic walking & $0.1 \pm 0.3$ & $0.1 \pm 0.3$ & $0.5 \pm 1.9$ \\
\hline
\end{tabular}

Table 5. Mean training volumes $(X \pm S D)$ of different training types.

\begin{tabular}{lcc}
\hline & $\begin{array}{c}\text { Training volume } \\
(\mathbf{m i n})\end{array}$ & $\begin{array}{c}\text { Training volume } \\
(\mathbf{k m})\end{array}$ \\
\hline Basic endurance & $119.5 \pm 32.9$ & $22.7 \pm 7.7$ \\
\hline Speed/interval & $109.4 \pm 18.1$ & $18.6 \pm 5.8$ \\
\hline Recovery & $74.8 \pm 33.1$ & $12.3 \pm 7.4$ \\
\hline
\end{tabular}


As there were errors in hear rate monitor data or the subject sometimes forgot to put the heart rate monitor on, 282 workouts (77\%) were entered to the analysis, which had the complete set of recorded data. Based on the "time in zone" method the subjects trained $71.8 \%$ in zone1, $27.1 \%$ in zone2 and $2.1 \%$ in zone 3 . According subjective assessment $74.1 \%$ of trainings were done in zone1, 19.0 in zone 2 and $8.0 \%$ in zone3. There were no significant differences between intensity distributions between zone1, but according to subjective scale subjects trained significantly less in zone 2 and significantly more in zone3 compared to time-in-zone method. Therefore, we also investigated if increasing the lower cut-off for zone3 (from 7 to 8 ) would be more precise in comparison of time-in-zone method. By doing this no significant differences were found between zone 2 and zone 3 measured by different methods (Table 6).

Table 7 presents the subjective assessments of training intensities indicated by coaches and athletes. Both subjective assessments correlated $(\mathrm{p}<0.05)$ highly with each other with the highest correlations found between zone2 $(\mathrm{r}=0.80)$ and interval trainings $(\mathrm{r}=0.71)$ and being lower for basic $(\mathrm{r}=0.25)$ and recovery trainings $(\mathrm{r}=0.35)$. It was interesting to note that for recovery trainings the average values were higher for athletes compared to coach, while for other types of training coaches values were higher compared to athletes. Differences however, were non-significant ( $p>0.05)$.

Table 6. Distributions of the training intensities according to time-in-zone method, 10-pt scale and the modified 10-pt scale of the subjects.

\begin{tabular}{lccc}
\hline & Time-in-zone (\%) & 10pt-scale(\%) & $\begin{array}{c}\text { Modified } \\
\text { 10-ptscale (\%) }\end{array}$ \\
\hline Zone1 & $71.8 \pm 2.1$ & $74.1 \pm 3.1$ & $74.1 \pm 3.1$ \\
\hline Zone2 & $27.1 \pm 1.4$ & $19.0 \pm 2.7^{*}$ & $22.6 \pm 2.9$ \\
\hline Zone3 & $2.1 \pm 0.4$ & $8.0 \pm 1.9^{*}$ & $4.4 \pm 1.5$ \\
\hline
\end{tabular}

* - significantly different of the time-in-zone method $(p<0.05)$

Table 7. Relationships between the subjective ratings of the coach and athlete.

\begin{tabular}{lcccc}
\hline \multicolumn{1}{c}{ Training type } & $\mathbf{n}$ & Coach & Athlete & $\mathbf{r}$ \\
\hline Basic endurance & 121 & $3.61 \pm 0.6$ & $3.50 \pm 1.0$ & $0.25, p=0.006$ \\
\hline Speed/interval & 61 & $6.64 \pm 2.0$ & $5.57 \pm 1.8$ & $0.71, p=0.000$ \\
\hline Recovery & 100 & $1.87 \pm 0.8$ & $2.17 \pm 0.8$ & $0.35, p=0.002$ \\
\hline Total & 282 & $3.65 \pm 2.0$ & $3.48 \pm 1.7$ & $0.80, p=0.000$ \\
\hline
\end{tabular}




\section{DISCUSSION}

The aim of the current study was to investigate how training intensities can be categorized using a 10-point rating scale. Secondly, it was our aim to investigate whether perceptions of the training intensity differ between the athlete and the coach. We found that the modified 10-point scale can be used to characterize training intensity distributions in young cross-country skiers.

Training intensities were higher in the current study compared to the adult cross-country skiers in Seiler and Kjerland [13] study, where the athletes trained $91 \%$ of their trainings in zone1 during the pre-competition period. The $71.8 \%$ of zone1 trainings accumulated in the current study did not reach to the suggested $80 \%$ that is considered optimal for endurance athletes [12]. In contrast, Esteve-Lanao et al. [6] found that high level runners achieved high results if training $71 \%$ of time below aerobic threshold (zone1). However, the athletes in the current study still trained most of the time below aerobic threshold that matches with the trainings of different endurance disciplines $[1,5,6,7,15,18]$.

If using the 10-pt scale for distributing training intensities to different intensity zones it revealed that subjects perceived higher intensities as more intensive compared to time-in-zone method. Therefore, we modified the lowest cut-off for zone3 from 7 to 8 , which yielded to non-significant differences in actual (heart rate) versus perceived (10-pt scale) intensities in zone2 and 3. As the initial 10-pt scale has been validated on adults, it may be suggested that younger athletes perceive higher intensities differently from adult athletes. In young athletes the training volume might be an excessive factor that might influence the perceived hardness of the training if training is long enough. In the current study, the volume of the single trainings was relatively high $(119.5 \pm 32.9 \mathrm{~min})$ that might have significant influence of the subjective assessment. However, the intensity factor might not be underestimated here. It was found in the current study that intensity distributions in zone1 were not different when compared by subjective and objective values ( $71,8 \%$ vs $74.1 \%$, respectively), while it was $91 \%$ and $76 \%$, respectively, in the study of Seiler and Kjerland [13]. Studies have argued that time-in-zone method overestimates the actual time at lower intensities and underestimates the time at higher intensities [12, 17]. Therefore, for young athletes the subjective ratings may slightly underestimate the "true" training intensities.

If adult athletes train one or two times a day almost during the year and this might result in overtraining, we could suggest that if young athletes train 
approximately 5 times in week, they have time for recovery. However, during training camps training load is increased often by $100 \%$ it could result in lowered adaptation of the athlete [16]. Therefore, we can not exclude the possibility that possible fatigue accumulation towards the end of the camp had influence also to the perceived training intensity. Unfortunately, we were not able to control this factor.

We also investigated what is the difference between the perception of the coach's intensity of the planned workout and the athlete perception after the same workout. In general, high correlations between those parameters were seen, however relationships were stronger at higher intensities and lower for basic and recovery trainings. One of the reasons for lower correlation at low intensity trainings can be attributed to the length of the training. Also we cannot eliminate the possibility that the athlete actually trained at slightly higher intensities than the coach planned. Similar result has been found also in high level athletes, where athlete may train too intensively at lower intensities [14]. The reason might be that the athlete is afraid of being training at low intensities and that the training load might not be enough. The fact that the coach's perception would be similar to athlete is considered important [12] in terms of the training effect. We may also speculate that if the initial similar perceptions of similar training by the coach and athlete should differ, training load should be overlooked to avoid over-or undertraining.

If to compare the perceptions of coach and athletes between different types of training, we see that for recovery trainings the perceptions were higher for athlete compared to the coach, while it was opposite for the other types of trainings. This indicates the importance of the monitoring of the recovery trainings, as athletes, especially at younger ages, are not able to estimate the need for such recovery trainings and very often the recovery targeted training may end up as relatively intensive.

Several limitations regarding this study have to be considered. As for some athletes the individual training zones were calculated, not measured by incremental test, could have the influence on the intensity zone distribution. Not using the lactate concentration for training intensity description should also considered as a limitation as it is difficult to evaluate how much in our study the time-in-zone method delineated from the actual intensities as described by Seiler and Kjerland [13].

In conclusion, using a subjective scale to describe training intensities provides a practical method in young athletes to characterize their training intensity. The method is also suitable for training zone distribution assessment and for comparison of coach and athlete perception of the training. 


\section{REFERENCES}

1. Billat VL, Demarle A, Slawinski J, Paiva M, Koralsztein JP. (2001) Physical and training characteristics of top-class marathon runners. Med Sci Sports Exerc, 33 (12): 2089-2097

2. Bompa T. Periodization. (1999) Theory and methodology of training. IL, Chicago: Hum Kin

3. Borg G, Jacobs I, Ceci R, Kaiser P. (1983) A category-ratio perceived exertionscale: relationship to blood and muscle lactates and heart rate. Med Sci Sports Exerc, 15: 523-528

4. Borresen J, Lambert MJ. (2009) The Quantification of Training Load, the Training Response and the Effect on Performance. Sports Med, 39 (9): 779-795

5. Esteve-Lanao J, Foster C, Seiler S, Lucia A. (2007) Impact of Training Intensity Distribution on Performance in Endurance Atheletes. J Strength Cond Res, 21 (3): 943-949

6. Esteve-Lanao J, San Juan AF, Earnest CP, Foster C, Lucia A. (2005) How do endurance runners actually train? Relationship with competition performance. Med Sci Sports Exerc, 37: 496-504

7. Fiskerstrand A, Seiler KS, Fiskerstrand A, Seiler KS. (2004) Training and performance characteristics among Norwegian international rowers 19702001. Scand J Med Sci Sports, 14: 303-310

8. Foster C, Florhaug JA, Franklin J, Gottschall L, Hrovatin LA, Parker S, Doleshal P, Dodge CA. (2001) New Approach to Monitoring Exercise Training. J Strength Cond Res, 15 (1): 109-115

9. Herman L, Foster C, Maher MA, Mikat RP, Porcari JP. (2006) Validity and reliability of the session RPE method for monitoring exercise training intensity. South African J Sport Med, 18 (1): 14-17

10. Meeusen R, Duclos M, Foster C, Fry A, Gleeson M, Nieman D, Raglin J, Rietjens G, Steinacker J, Urhausen A. (2013) Prevention, diagnosis and treatment of the overtraining syndrome: Joint consensus statement of the European College of Sport Science (ECSS) and the American College of Sport Medicine (ACSM). Eur J Sport Sci, 13 (1): 1-24

11. Minganti C, Ferragina A, Demarie S, Verticchio N, Meeusen R, Piacentini MF. (2011) The use of session RPE for interval training in master endurance athletes: should rest be included? J Sports Med Phys Fitness, 51 (4): 547-554

12. Seiler S. (2010) What is the best practice for Training Intensity and Duration Distribution in Endurance Athletes. Int J Sports Physiol Perform, 5: 276-291

13. Seiler KS, Kjerland GO. (2006) Quantifying training intensity distribution in elite endurance athletes: is there evidence for an "optimal" distribution? Scand J Med Sci Sports, 16: 49-56 
14. Seiler S, Tønnessen E. (2009) Intervals, Thresholds, and Long Slow Distance: the Role of Intensity and Duration in Endurance Training. Sport Sci, 13: $32-53$

15. Smith RM, Spinks WL. (1995) Discriminant analysis of biomechanical differences between novice, good and elite rowers. J Sports Sci, 13: 377-385

16. Steinacker JM, Lormes W, Lehmann M, Altenburg D. (1998) Training of rowers before world championships. Med Sci Sports Exerc, 30: 1158-1163

17. Sylta Ø, Tønnessen E, Seiler S. (2014) From Heart Rate to Training Quantification: A Comparison of 3 Methods of Training-Intensity Analysis. Int J Sports Physiol Perform, 9: 100-107

18. Zapico AG, Calderon FJ, Benito PJ, Gonzalez CB, Parisi A, Pigozzi F, Di Salvo V. (2007) Evolution of physiological and haematological parameters with training load in elite male road cyclists: a longitudinal study. J Sports Med Phys Fitness, 47: 191-196

\section{Correspondence to:}

Jarek Mäestu, PhD

Institute of Sport Biology and Physiotherapy

University of Tartu

Jakobi 5, 51014 Tartu, Estonia

Telephone: +372 7375372

E-mail: jarek.maestu@ut.ee 